\title{
In vitro activity of Indian almond (Terminalia catappa) leaf crude extracts against selected dermatophytes
}

\author{
Roxanne Joy B. Colendres and Carl Leonard M. Pradera ${ }^{1 *}$
}

Fungal infections caused by Trichophyton mentagrophytes, Aspergillus fumigatus , and Malassezia pachydermatis are among the major contributors to multisystemic health problems such as dermatitis, otitis, and respiratory disorders among humans and animals. This study was conducted to determine the in vitro antifungal activity of Terminalia catappa leaf crude aqueous and ethanolic extracts against these fungal pathogens by measuring the zone of inhibition (ZI) using the agar well diffusion technique. Qualitative phytochemical screening tests were also performed to determine bioactive compounds present in the plant extract.

Results show that the plant's crude aqueous (CAE) and ethanolic extracts (CEE) were found to be effective against all test fungi. M. pachydermatis showed susceptibility towards CAE and CEE from T1 (100\%), T2 (75\%), T3 (50\%) and T4 $(25 \%)$, with the highest mean ZI of $18.33 \mathrm{~mm}$ and 13.33 , respectively. On the other hand, T. mentagrophytes was inhibited by CAE and CEE at T1 (100\%), T2 $(75 \%)$ and T3 (50\%) with the highest mean $\mathrm{Zl}$ of $9.67 \mathrm{~mm}$ and $10.33 \mathrm{~mm}$, respectively. At the same time, it was observed that $A$. fumigatus had reactive sensitivity towards CAE and CEE at T1 $(100 \%)$ and T2 (75\%), with the highest mean ZI of $9.33 \mathrm{~mm}$ and $10.33 \mathrm{~mm}$, respectively. Moreover, phytochemical tests showed that the plant's leaf crude extracts contain alkaloids, saponins, and tannins, which could potentially inhibit fungal growth.

Keywords: Antifungal, Aspergillus fumigatus, bioactive compounds, Malassezia pachydermatis, Trichophyton mentagrophytes, zone of inhibition

${ }^{1}$ College of Veterinary Medicine, Visayas State University, Baybay City, Leyte

\footnotetext{
*Corresponding Author. Address: College of Veterinary Medicine, Visayas State University, Baybay City, Leyte; Email: carl.pradera@vsu.edu.ph
} 


\section{INTRODUCTION}

Dermatophytosis is known as the most common fungal infection in companion animals, such as dogs and cats (Moriello et al 2017). This disease is commonly caused by Trichophyton mentagrophytes, Aspergillus fumigatus and Malassezia pachydermatis (Mercantini et al 1995, Seyedmousavi et al 2015). As a zoonotic disease, it accounts for a high percentage of health problems among humans and animals (Mederle et al 2010, Pasquetti et al 2017). Specifically, fungal infection caused by Trichophyton mentagrophytes is characterized by alopecia with erythema and desquamation of epithelial cells. On the other hand, Aspergillus fumigatus, a saprophytic filamentous fungus, can cause localized skin infection to multisystemic diseases that can be fatal, as well as allergic response to inhaled conidia (Seyedmousavi et al 2015) while Malassezia pachydermatis is a lipophilic yeast that is commonly associated with otitis externa and seborrheic dermatitis in dogs and cats (Cristina and Degi 2009).

To address these dermatological issues, there are several synthetic antifungal drugs that are readily available in the market but is quite expensive and have shown to develop resistance against these pathogens (Bustamante et al 2020, Chen et al 2020). Moreover, the continuous rise of life-threatening invasive fungal infections caused by Trichophyton mentagrophytes, Aspergillus fumigatus, and Malassezia pachydermatis have caught the attention of medical scientists to expand antifungal drug researches (Andriole 2000). However the production of new antifungal drugs takes more time to develop and requires extensive clinical studies before they can be of general use (Roemer and Krysan 2014). Hence, ethnoveterinary products and the development of alternative herbal preparations that are safe, economical, and readily available is being explored nowadays (Stein et al 2005), one of which is Indian almond (Terminalia catappa) or locally known as Talisay.

Several studies have already been explored for the potential medicinal properties of $T$. catappa. These include but not limited to the antimicrobial, antifungal, antioxidant and even potential cytotoxic effects and phytochemical properties of the plant extracts (Espinosa Ruiz et al 2012, Terças et al 2017). In a study that was conducted by Salares and Balala (2018), it was able to demonstrate the antimicrobial activity of this plant's leaf crude ethanolic extract. Specifically, results have shown susceptibility of both gram- positive and gram-negative bacteria at $5,000 \mu \mathrm{g} \mathrm{mL} \mathrm{m}^{-1}$ to $10,000 \mu \mathrm{g} \mathrm{mL}^{-1}$ crude ethanolic concentration. In addition, Candida albicans was found to be more sensitive as compared to Microsporum canis at $78.12 \mu \mathrm{g} \mathrm{mL}^{-1}$ minimum inhibitory concentration. Moreover, the antifungal efficacy of $T$. catappa wood and bark aqueous, ethyl acetate, and hexane extracts against several fungal pathogens have also been documented wherein 50,100 and $150 \mu \mathrm{L}$ of the wood aqueous extracts were found to be effective against Aspergillus fumigatus, Microsporum gypseum, Mucor sp., Penicillium sp., Rhizopus sp., Scopulariops sp., and Sporothrix scheckii, while the bark aqueous extracts of the same concentrations were effective against Candida albicans, Ganoderma sp., Sporothrix scheckii and Trichoderma species. In addition, $28 \mathrm{~mm}$ per $150 \mu \mathrm{L}$ of the wood ethyl acetate extracts revealed a maximum inhibitory activity against $A$. fumigatus, Scopulariops sp., and M. gypseum, while $26 \mathrm{~mm}$ per $150 \mu \mathrm{g} \mathrm{mL}^{-1}$ and $24 \mathrm{~mm}$ per $150 \mu \mathrm{L}$ of the bark ethyl acetate extracts showed a maximum inhibitory activity against $A$. fumigatus and $M$. gypseum, respectively 
(Gandhi et al 2015). The in vitro antifungal activities of T. catappa and T. arjuna methanolic and ethanolic leaf extracts against Aspergillus niger, Alternaria alternata, Curvularia lunata and Trichophyton tonsurans were also reported(Mandloi et al 2013).

With the various studies of the promising therapeutic properties of $T$. catappa extracts, our study focused on the in vitro antifungal activity of the plant's leaf crude aqueous and ethanolic extracts against Trichophyton mentagrophytes, Aspergillus fumigatus, and Malassezia pachydermatis. Hence, the results of this study could provide essential information for the potential in vitro pharmacologic effects of the plant leaf crude extracts against these fungal agents by measuring its zone of inhibition and determining the presence of phytochemicals and bioactive compounds that could be responsible for the antifungal property of the plant leaf crude ethanolic and aqueous extracts. Furthermore, this study can serve as a benchmark data for further in vivo tests and clinical trials in order to formulate ethnoveterinary products with effective antifungal properties.

\section{MATERIALS AND METHODS}

\section{Preparation of Leaf Crude Extract}

Collection and Processing of Plant Material. Mature Indian almond leaves were brought and presented to the Department of Biological Sciences, Visayas State University for proper botanical identification. After which, leaves were washed thoroughly, cut into small pieces, and air-dried at room temperature until at least $80 \%$ of the moisture content was removed and they became crisp and brittle. Dried leaves were preserved in a zip lock plastic, and stored at room temperature for three days until use(Ballentes and Pradera 2019).

Extraction of $\boldsymbol{T}$. catappa Leaf. This procedure was done at the Diagnostic Laboratory of the College of Veterinary Medicine, Visayas State University. Following the methods applied by Fernandez Jr et al (2013) with some modifications, dried leaves of Indian almond were pulverized in a blender before they were extracted either using distilled water or absolute ethanol as solvent systems, accordingly. About $250 \mathrm{~g}$ of dried and pulverized leaves were soaked in a beaker containing $750 \mathrm{~mL}$ of absolute ethanol (1:3w/v) and was left to stand on a bench for $48 \mathrm{~h}$. After which, the leaves were filtrated using a laboratory grade filter paper No. 54 $\left(\right.$ Whatman $^{\oplus}$ ) into an Erlenmeyer flask. Similarly, a separate $250 \mathrm{~g}$ of dried leaves were soaked in a beaker containing $750 \mathrm{~mL}$ of distilled water and was processed as above. The filtrates were identified as crude ethanolic extract (CEE) and crude aqueous extract $(\mathrm{CAE})$, respectively. These were further concentrated separately in a rotary evaporator for $1-2 \mathrm{~h}$ at $60^{\circ} \mathrm{C}$ and $40^{\circ} \mathrm{C}$, respectively. The CEE and CAE were transferred separately to amber bottles and were left to stand at room temperature for $24 \mathrm{~h}$ to allow solvents to evaporate. The extracts were kept under $4^{\circ} \mathrm{C}$ for one day until needed for the assay. 


\section{Qualitative Phytochemical Screening of T. catappa Leaf Crude Extracts}

T.catappa leaf crude ethanolic and aqueous extracts were individually subjected to several phytochemical tests at the Microbiology Laboratory of the College of Veterinary Medicine, Visayas State University to classify the bioactive components present. Following the methods performed by Harborne (1984) and Claustra et al (2005) with some modifications, these screening tests were conducted to detect the presence of alkaloids, flavonoids, saponins, terpenoids, and tannins in both crude ethanolic and aqueous extracts. Specifically, to screen for alkaloids, two drops of Dragendorff or Wagner's reagent were added to two $\mathrm{mL}$ of the test solution and the formation of orange precipitates indicate the presence of these bioactive compounds. Moreover, Bate-Smith and Metacalf Test was used to determine the presence of flavonoids. In here, one $\mathrm{mL}$ of the test solution was added with two drops of $80 \%$ ethyl alcohol and hydrochloric acid. After 15 mins of submerging the mixture in a hot water bath, a red or violet coloration indicates the presence of leucoanthocyanins and a pink to yellow-orange coloration indicates the presence of anthocyanins, both of which are flavonoids. Froth test was used to screen for saponins. As the word implies for this test, a copious lather formation indicates the presence of saponins after adding distilled water into two $\mathrm{mL}$ of the test solution. Furthermore, a reddish-brown coloration confirms the presence of terpenoids via Salkwoski Test after adding two drops of chloroform and concentrated sulfuric acid into two $\mathrm{mL}$ of the test solution. Lastly, Ferric chloride Test was used to screen for tannins in which two $\mathrm{mL}$ of the test solution was added with two drops of ferric chloride. After 1-2min, a color change of bluish-black and brownish-green indicate the presence of condensed tannins. The chemicals and reagents used during phytochemical screening tests were provided by the Department of Pure and Applied Chemistry, Visayas State University.

\section{Preparation of Test Organisms}

The preparation of test organisms followed standard laboratory procedures as described by Ballentes and Pradera (2019) with some modifications. Trichophyton mentagrophytes, Aspergillus fumigatus, and Malassezia pachydermatis were obtained from the stock cultures of the Microbiology Laboratory of the College of Veterinary Medicine, Visayas State University. T. mentagrophytes and A. fumigatus were sub-cultured onto Sabouraud dextrose agar slants and then incubated for 7 days at $27^{\circ} \mathrm{C}$. On the other hand, M. pachydermatis was streaked onto Sabouraud dextrose agar and incubated for one day at $37^{\circ} \mathrm{C}$.

Preparation of Fungal Suspensions. Inoculum suspension of each isolate of the designated fungi was prepared from 7-day-old cultures grown on Sabouraud dextrose agar slants. To dislodge the conidia of $T$. mentagrophytes and $A$. fumigatus from the hyphal mat, the fungal colonies were covered with $10 \mathrm{~mL}$ of sterile water and the surface was probed gently using the tip of a sterile loop. Then, the conidial and hyphal fragments were transferred to a sterile tube and permitted to settle for 10min and the upper homogenous suspension was collected. Subsequently, a loopful amount of $M$. pachydermatis from the slant was moved to $10 \mathrm{~mL}$ of Sabouraud dextrose broth with $0.2 \mathrm{~mL}$ Tween 80 and incubated for several 
hours at $37^{\circ} \mathrm{C}$ until the turbidity was set to $9.5 \mathrm{McF}$ Frland turbidity standard. This was done to provide an optical density similar to the density of a bacterial suspension at $1.5 \times 10^{8}$ colony-forming unit (CFU) that is used for agar well diffusion method(Fernández-Torres et al 2002).

Determination of the density of the Conidia. This step followed the method employed by Oliveira et al (2015) and Ballentes and Pradera (2019) with some modifications. From serially diluted suspension (1:10), a small amount was taken and placed on a hemocytometer to quantify the desired conidia for the assay. At low power objective, the number of conidia was totaled at the middle quadrant using only 5 of the 25 squares in the middle quadrant. Manipulation was made in the previously prepared suspension of known density to come up with the desired number of conidia by further dilution. The total number of conidia was computed using this formula:

Cell concentration $/ \mathrm{mL}=$ Total cell count in 5 squares $\times 50,000 \times$ dilution factor

\section{Antifungal Assay of Crude Extract}

Agar Well Diffusion Technique. Following the standard laboratory procedures and as described by Ballentes and Pradera (2019), Sabouraud's Dextrose Agar (SDA) was used as culture medium for the assay. For T. mentagrophytes, one $\mathrm{ml}$ of fungal inoculum was poured into the sterile petri plates using a sterile pipette and $15 \mathrm{~mL}$ molten SDA were added. The plates were rotated eight times each in clockwise rotation and in vertical direction to evenly distribute the agar and test organisms. Once hardened, wells were made on the agar using a borer with a diameter of $7 \mathrm{~mm}$. The same method was also applied for A. fumigatus. For $M$. pachydermatis, SDA was hardened first and the test organism was swabbed. About $0.7 \mathrm{~mL}$ of the varying concentrations of $T$. catappa leaf crude ethanolic and aqueous extracts were placed into each corresponding well. The preparation was incubated at $27^{\circ} \mathrm{C}$ for 4 days for Trichophyton mentagrophytes and Aspergillus fumigatus and at $37^{\circ} \mathrm{C}$ for 2 days for Malassezia pachydermatis. After incubation, the zone of inhibition ( $\mathrm{ZI})$ was measured from side to side using a metric ruler $(\mathrm{mm})$ and the results were compared to the standard measurement set by the Clinical Laboratory Standard Insititute.

\section{Experimental Design}

The experiment was laid out in a Completely Randomized Design (CRD). There were seven treatment groups, replicated three times, with seven plastic wells in each replicate. The treatment groups are shown below:

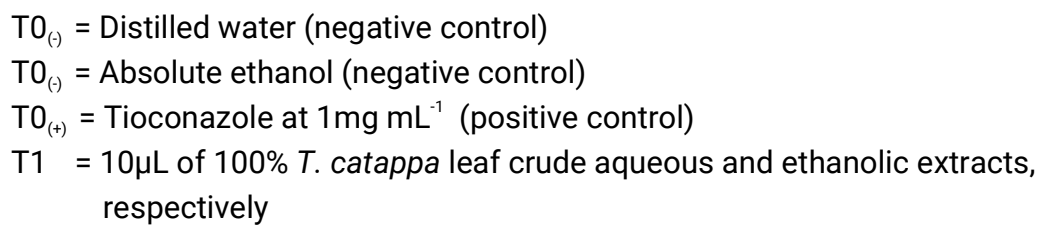


$\mathrm{T} 2=10 \mu \mathrm{L}$ of $70 \% \mathrm{~T}$. catappa leaf crude aqueous and ethanolic extracts, respectively

$\mathrm{T} 3=10 \mu \mathrm{L}$ of $50 \% \mathrm{~T}$. catappa leaf crude aqueous and ethanolic extracts, respectively

$\mathrm{T} 4=10 \mu \mathrm{L}$ of $25 \%$. T. catappa leaf crude aqueous and ethanolic extracts, respectively

These concentrations were used after a pilot test was conducted prior to its final assay.

The zone of inhibition ( $\mathrm{ZI}$ ), a circular area around the spot of the antifungal drugs in which the fungal colonies do not grow (Cooper 1955, Hsu and Lockwood 1969), was measured using a metric ruler ( $\mathrm{mm}$ ) and the breakpoints for disc diffusion method recommended by the Clinical Laboratory Standard Institute was used with some modifications. Specifically, a clear zone of inhibition measuring $<0.125 \mathrm{~mm}, 0.25-0.5 \mathrm{~mm}$, and $>1.00 \mathrm{~mm}$ were considered susceptible, susceptibledose dependent, and resistant, respectively (Rex et al 1997). Data were analyzed using Analysis of Variance (ANOVA) and significant differences ( $p$-value:<0.05) between treatment means were determined and compared by way of Tukey's Honestly Significant Difference (HSD) using the SPSS statistical software program (Verma 2012).

\section{RESULT AND DISCUSSION}

The antifungal activities of the varying concentrations of $T$. catappa leaf crude aqueous extract (CAE) and crude ethanolic extract (CEE) are listed in Table 1. Results showed that the plant's leaf crude aqueous and ethanolic extracts were both effective against the in vitro growth of Malassezia pachydermatis from T1 (100\%) to T4 (25\%), Trichophyton mentagrophytes from T1 (100\%) to T3 (75\%), and Aspergillus fumigatus from T1 (100\%) to T2 (50\%). This has been observed by measuring its mean zone of inhibition ( $\mathrm{ZI}$ ) using these concentrations. For instance, the CAE showed a complete inhibitory effect at $100 \% \quad(Z I=18.33 \mathrm{~mm}), 75 \%$ $(Z \mathrm{I}=15 \mathrm{~mm}), 50 \%(\mathrm{Zl}=13.67 \mathrm{~mm})$ and $25 \%(\mathrm{ZI}=9.33 \mathrm{~mm})$ concentrations against $M$. pachydermatis. The same result was also observed using CEE but with less sensitivity such that T1 (100\%), T2 (50\%), T3 (50\%) and T4 (25\%) yielded a mean zone of inhibition of $13.33 \mathrm{~mm}, 10.67 \mathrm{~mm}, 8.67 \mathrm{~mm}$ and $8 \mathrm{~mm}$, respectively. The promising antifungal properties of Terminalia catappa shown in this study conforms with the results presented by several researches (Ahon et al 2011, Gandhi et al 2015, Rubini et al 2013). In one study, it was documented that the plant's leaf ethanolic and methanolic fractions are effective against Aspergillus niger, Trichophyton tonsurans, Curvularia lunata and Alternaria alternata with varying levels of sensitivity (Mandloi et al 2013). A similar finding was also obtained to assess the antifungal activity against Candida albicans using gas chromatography coupled to mass spectrometry ionization and hydrogen nuclear magnetic resonance techniques (Terças et al 2017). Moreover, the antifungal activity of the same plant extracts against Candida albicans, Aspergillus fumigatus and 
Trichophyton mentagrophytes has been optimized (Bognan et al 2016). However the present study also noted that the positive control, Tioconazole $\left(1 \mathrm{mg} \mathrm{mL}^{-1}\right)$, is the most effective among all treatment groups based on its mean zone of inhibition, and is statistically significant $(p$-value:<0.05) compared to the varying concentrations of the plant's leaf crude extracts against all fungal pathogens. This means that despite the efficacy and varying reactive sensitivity of the test fungi towards T.catappa leaf crude solvent extracts, the positive control, Tioconazole at $1 \mathrm{mg} \mathrm{mL}^{-1}$, is still a more effective therapeutic drug. Therefore, other plant parts and solvent systems can also be explored as a more potential source of therapeutic agents which may lead in the ongoing search for antimicrobial botanicals (Manzur et al 2011).

Table 1. Zone of inhibition $(\mathrm{mm})$ between each treatment group against test fungi and between crude aqueous and ethanolic extracts

\begin{tabular}{|c|c|c|c|c|c|c|}
\hline \multirow[b]{3}{*}{ Treatment } & \multicolumn{6}{|c|}{ Zone of Inhibition (mm) } \\
\hline & \multicolumn{2}{|c|}{ Malassezia pachydermatis } & \multicolumn{2}{|c|}{$\begin{array}{l}\text { Trichophyton } \\
\text { mentagrophytes }\end{array}$} & \multicolumn{2}{|c|}{ Aspergillus fumigatus } \\
\hline & Aqueous & Ethanolic & Aqueous & Ethanolic & Aqueous & Ethanolic \\
\hline $\begin{array}{l}\mathrm{TO}_{(-)} \text {distilled water, } \\
\text { ethanol }\end{array}$ & 0 & 0 & 0 & 0 & 0 & 0 \\
\hline $\begin{array}{l}\mathrm{TO}_{(+)} \text {Tioconazole } \\
(1 \mathrm{mg} / \mathrm{mL})\end{array}$ & $29.67 \pm 0.33^{a}$ & $27.33 \pm 0.33^{\mathrm{a}}$ & $24.33 \pm 0.67^{\mathrm{a}}$ & $25 \pm 0.58^{\mathrm{a}}$ & $23 \pm 0.58^{a}$ & $23.67 \pm 0.67$ \\
\hline $\mathrm{T} 1(100 \%)$ & $18.33+0.88^{b}$ & $13.33 \pm 0.88^{b}$ & $9.67 \pm 0.33^{b}$ & $10.33 \pm 0.88^{b}$ & $9.33 \pm 0.33^{b}$ & $10.33 \pm 0.33$ \\
\hline T2 (75\%) & $15 \pm 1^{c}$ & $10.67 \pm 0.67^{c}$ & $8.33 \pm 0.33^{b c}$ & $9.33 \pm 0.33^{\mathrm{bc}}$ & $8^{c}$ & $8.67 \pm 0.33$ \\
\hline T3 (50\%) & $13.67 \pm 0.67^{c}$ & $8.67 \pm 0.33^{\text {cd }}$ & $8^{c}$ & $8.33 \pm 0.33^{c}$ & 0 & 0 \\
\hline $\mathrm{T} 4(25 \%)$ & $9.33 \pm 0.33^{\mathrm{d}}$ & $8^{d}$ & 0 & 0 & 0 & 0 \\
\hline
\end{tabular}

$\mathrm{n}=5$; Means with different letter superscript are significantly different ( $p$-value:<0.05).

Generally, it is also observed that the efficacy of $T$. catappa leaf crude aqueous and ethanolic extracts followed a dose-dependent manner. This means that as the concentration increases, the zone of the inhibition also increases such that, T1 $(100 \%)$ has the highest mean zone of inhibition among all concentrations. Specifically, M. pachydermatis was shown to have higher sensitivity towards crude aqueous extracts compared to crude ethanolic extracts with T1 (100\%) having the highest mean zone of inhibition $(18.33 \mathrm{~mm})$. Inversely, T. mentagrophytes and $A$. fumigatus were more sensitive to the plant's leaf CEE than CAE. For $T$. mentagrophytes, the highest mean zone of inhibition was noted at T1 $(\mathrm{ZI}=10.33 \mathrm{~mm})$ followed by $\mathrm{T} 2(\mathrm{ZI}=9.33 \mathrm{~mm})$ and $\mathrm{T} 3(\mathrm{ZI}=8.33 \mathrm{~mm})$ while the highest mean zone of inhibition against $A$. fumigatus was also observed at T1 (ZI=10.33mm) followed by $\mathrm{T} 2(\mathrm{ZI}=8.67 \mathrm{~mm})$. 


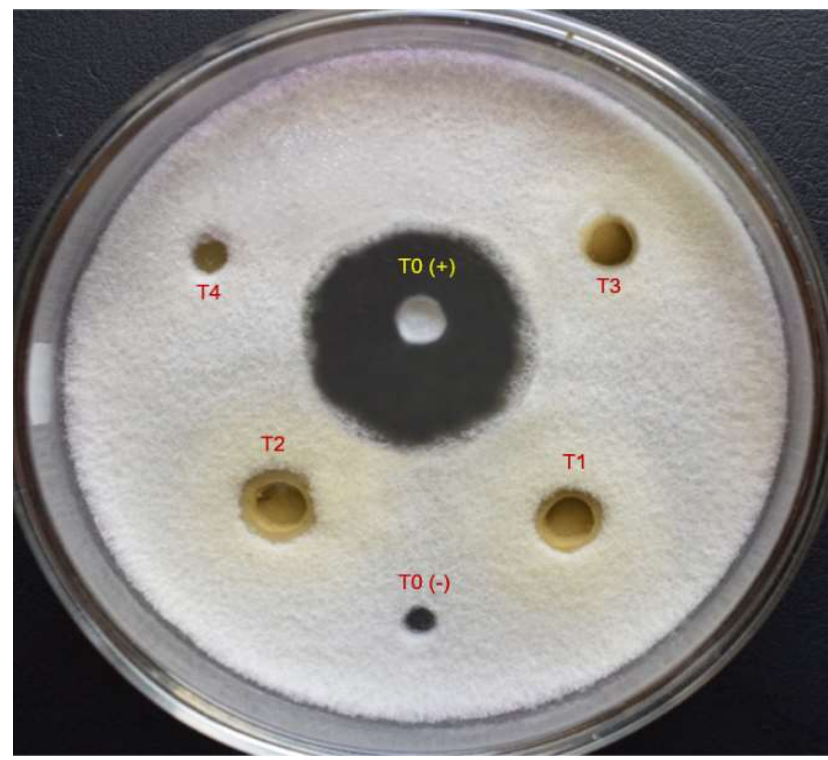

Figure 1. Zone of inhibition (mm) of Trichophyton mentagrophytes treated with varying concentrations of Terminalia catappa leaf crude ethanolic and aqueous extracts

The chemical and biological properties of a plant extract are significantly influenced by the solvent system that is used for extraction. Choice of solvent for extraction of plant material depends on solubility and type of compounds intended to isolate -(Cheok et al 2012, Rebey et al 2012). Ethanol is considered as an ideal solvent for initial extraction because almost all of the antifungal bioactive compounds that can be extracted using this solvent are aromatic or saturated organic -(Das et al 2010, Turkmen et al 2006). That is why, M. pachydermatis is more susceptible towards the plant's leaf crude aqueous extract while $T$. mentagrophytes and $A$. fumigatus have higher reactive sensitivity by using crude ethanolic extract. Since both solvent systems (ethanol and distilled water) used in this study are polar in nature (Barbouchi et al 2020), there is a higher chance to extract almost similar phytochemical compounds (Cowan 1999) as shown in Table 2. These bioactive compounds may be responsible for the antifungal activities of the plant extracts -(Cordell 2011). Specifically, tannins are known to inhibit the extracellular microbial enzymes and deprive the substrates and metal ions required for microbial growth (Cowan 1999) while alkaloids and saponins are not only capable of complexing extracellular proteins but also of breaking the microbial membranes causing cell death (Lalitha and Venkataraman 1991, Wang et al 2020, Zhang et al 2006). The present study was conducted using qualitative analysis of the bioactive compounds only, and more sophisticated methods are suggested to be performed to justify these claims. 
Table 2. Qualitative phytochemical tests of $T$. catappa leaf crude aqueous and ethanolic extracts

\begin{tabular}{|c|c|c|c|c|c|}
\hline \multirow{2}{*}{\multicolumn{2}{|c|}{ Phytochemicals }} & \multirow{2}{*}{ Tests } & \multirow{2}{*}{ Descriptions } & \multicolumn{2}{|c|}{ Reactions } \\
\hline & & & & $\mathrm{CAE}$ & CEE \\
\hline \multicolumn{2}{|l|}{ Terpenoids } & Salkowski Test & Red brownish coloration & - & - \\
\hline \multicolumn{2}{|l|}{ Saponins } & Froth Test & $\begin{array}{l}\text { Formation of froth or } \\
\text { bubbles }\end{array}$ & - & ++ \\
\hline \multicolumn{2}{|l|}{ Tannins } & Ferric chloride Test & $\begin{array}{l}\text { Bluish black and } \\
\text { brownish green } \\
\text { coloration }\end{array}$ & +++ & ++++ \\
\hline \multicolumn{2}{|l|}{ Flavonoids } & $\begin{array}{l}\text { Bate-smith and Metacalf } \\
\text { Test }\end{array}$ & $\begin{array}{l}\text { Red to violet or pink to } \\
\text { yellow orange coloration }\end{array}$ & - & - \\
\hline \multicolumn{2}{|l|}{ Alkaloids } & Wagner's Test & $\begin{array}{l}\text { Orange to reddish brown } \\
\text { precipitates }\end{array}$ & t++ & ++++ \\
\hline $\begin{aligned} \text { Legends: } & \text { C } \\
& \mathrm{C} \\
& + \\
& + \\
& + \\
& + \\
& -\end{aligned}$ & \multicolumn{2}{|c|}{$\begin{array}{l}\text { CAE: crude aqueous extract } \\
\text { CEE: crude ethanolic extract } \\
\text { ++++ Maximum amount } \\
\text { +++ Good amount } \\
\text { ++ Moderate amount } \\
\text { + Low amount } \\
\text {-Absent }\end{array}$} & & & \\
\hline
\end{tabular}

\section{CONCLUSIONS}

In general, both the crude ethanolic (CEE) and aqueous (CAE) leaf extracts of Terminalia catappa were shown to have promising antifungal properties against Trichophyton mentagrophytes, Aspergillus fumigatus and Malassezia pachydermatis based on the observed zone of inhibition. More specifically, $T$. mentagrophytes were susceptible to T1 (100\%), T2 (75\%), T3 (50\%) and T4 (25\%), while A. fumigatus were susceptible at T1 (100\%), T2 (75\%) and T3 (50\%). Additionally, T1 (100\%) and T2 (75\%) of the plant's leaf crude extracts were effective against $M$. pachydermatis. Moreover, the CAE were able to draw out tannins and alkaloids while the CEE got saponins, tannins and alkaloids. However, a higher mean zone of inhibition exhibited by the plant's leaf crude ethanolic extract compared to its crude aqueous extract would indicate that the former solvent system is more effective in extracting potential antifungal agents against $M$. pachydermatis. Being said, the crude ethanolic extract is also more effective in extracting potential bioactive compounds against $T$. mentagrophytes and $A$. fumigatus. For further related studies, different methods in the application of extract may be employed in antifungal assay as well as determination of the Minimum Inhibitory Concentration (MIC). Furthermore, using of other solvent systems in extracting the bioactive compounds can also be recommended.

\section{ACKNOWLEDGMENT}

The authors are thankful to all faculty and staff of the College of Veterinary Medicine, Visayas State University, headed by Dr. Eugene B. Lañada for the unending support during the conduct of this study. Moreover, sincere gratitude is 
given to Dr. Jane P. Dautil for her critical and scientific comments and suggestions especially in revising and polishing the content of this study.

\section{REFERENCES}

Ahon MG, Akapo-Akue JM, Kra MA, Ackah JB, Zirihi NG \& Djaman JA. 2011. Antifungal activity of the aqueous and hydro-alcoholic extracts of Terminalia superba Engl. on the in vitro growth of clinical isolates of pathogenic fungi. Agriculture and Biology Journal of North America 2(2):250-257

Andriole VT. 2000 . Current and future antifungal therapy: new targets for antifungal therapy. International Journal of Antimicrobial Agents 16(3):317-321

Ballentes VSB and Pradera CLM. 2019. In vitro activity of asthma plant (Euphorbia hirta linnaeus) leaf extract against Trichophyton mentagrophytes, Candida albicans and Malassezia pachydermatis. Philippine Journal of Veterinary and Animal Sciences 45(2):126-131

Barbouchi M, Elamrani K \& El Idrissi M. 2020. A comparative study on phytochemical screening, quantification of phenolic contents and antioxidant properties of different solvent extracts from various parts of Pistacia lentiscus L. Journal of King Saud University-Science 32(1):302-306

Bognan AJAA, Guillaume YY, Annick K, Josette AD \& Joseph DA. 2016. Optimization of antifungal activity of Terminalia catappa (Combretacae) on the in vitro growth of Candida albicans, Aspergillus fumigatus and Trichophyton mentagrophytes. International Journal of Pharma Research and Health Science 4(5):1385-1388

Bustamante B, Illescas LR, Posadas A \& Campos PE. 2020. Azole resistance among clinical isolates of Aspergillus fumigatus in Lima-Peru. Medical Mycology 58(1):54-60

Chen Y, Dong F, Zhao J, Fan H, Qin C, Li R, Verweij PE, Zheng Y \& Han L. 2020. High azole resistance in Aspergillus fumigatus isolates from strawberry fields, China, 2018. Emerging Infectious Diseases 26(1):81-89

Cheok CY, Chin NL, Yusof YA \& Law CL. 2012. Extraction of total phenolic content from Garcinia mangostana linn. hull. I. Effects of solvents and UV-vis spectrophotometer absorbance method. Food and Bioprocess Technology 5(7):2928-2933

Claustra AL, Madulid RS, Aguinaldo AM, Espeso El, Guevara BQ, Nonato MG, Santos MAG, de Castro-Bernas G, Gonzales RE \& del Castillo-Solevilla RC. 2005. A guidebook to plant screening: phytochemical and biological. University of Santo Tomas Publishing House, Espana, Manila

Cooper K. 1955. Theory of antibiotic inhibition zones in agar media. Nature 176(4480):510-511

Cordell GA. 2011. Phytochemistry and traditional medicine - a revolution in process. Phytochemistry Letters 4(4):391-398

Cowan MM. 1999. Plant products as antimicrobial agents. Clinical Microbiology Reviews 12(4):564-582

Cristina RT and Degi J. 2009. Diagnosis and treatment of malassezia infections in dog and cat. Fungi and Mycotoxins 3(1):250-259

Das K, Tiwari R \& Shrivastava D. 2010. Techniques for evaluation of medicinal plant products as antimicrobial agents: current methods and future trends. Journal of Medicinal Plants Research 4(2):104-111 
Espinosa Ruiz, R, Herrera Isla L, Bravo Sánchez L, Hernandez Aro M, Torres García S, Ramos González Y \& Espinosa Mill M. 2012. Synergic effect of tannins and flavonoids in Terminalia catappa L. on the mycelial growth of Rhizoctonia solani Kühn and Sclerotium rolfsii Sacc. Fitosanidad 16(1):27-32

Fernandez TJ Jr, Portugaliza HP, Braga FB, Vasquez EA, Acabal AD, Divina BP \& Pedere WB. 2013. Effective Dose (ED) and quality control studies of the Crude Ethanolic Extract (CEE) mixture of Makabuhay, Caimito and Makahiya (MCM) as dewormer for goats against Haemonchus contortus. Asian Journal of Experimental Biological Sciences 4(1):28-35

Fernández-Torres B, Cabanes FJ, Carrillo-Munoz AJ, Esteban A, Inza I, Abarca L \& Guarro J. 2002. Collaborative evaluation of optimal antifungal susceptibility testing conditions for dermatophytes. Journal of Clinical Microbiology 40(11):3999-4003

Gandhi P, Venkatalakshmi PP \& Brindha P. 2015. Efficacy of Terminalia catappa L. wood and bark against some fungal species. International Journal of Current Microbiology and Applied Sciences 4(9):74-80

Harborne JB. 1984. Phytochemical methods. a guide to modern techniques of plant analysis. Springer Netherlands

Hsu S and Lockwood J. 1969. Mechanisms of inhibition of fungi in agar by streptomycetes. Microbiology 57(2):149-158

Lalitha T and Venkataraman L. 1991. Antifungal activity and mode of action of saponins from Madhuca butyracea Macb. Indian Journal of Experimental Biology 29(6):558-562

Mandloi S, Srinivasa R, Mishra R \& Varma R. 2013. Antifungal activity of alcoholic leaf extracts of Terminalia catappa and Terminalia arjuna on some pathogenic and allergenic fungi. Advances in Life Science and Technology 8(1):25-27

Manzur A, Raju A \& Rahman S. 2011. Antimicrobial activity of Terminalia catappa extracts against some pathogenic microbial strains. Pharmacology and Pharmacy 2(04):299-305

Mederle N, Darabus G, Morariu S, Oprescu I, Indre D \& Balint A. 2010. Epidemiological aspects in human and cat microsporia. Lucrari Stiintifice Universitatea de Stiinte Agricole a Banatului Timisoara, Medicina Veterinara 43(1):61-63

Mercantini R, Moretto D, Palamara G, Mercantini P \& Marsella R. 1995. Epidemiology of dermatophytoses observed in Rome, Italy, between 1985 and 1993. Mycoses 38(9-10):415-419

Moriello KA, Coyner K, Paterson S \& Mignon B. 2017. Diagnosis and treatment of dermatophytosis in dogs and cats: clinical consensus guidelines of the World Association for Veterinary Dermatology. Veterinary Dermatology 28(3):266268

Oliveira DGP, Pauli G, Mascarin GM \& Delalibera I. 2015. A protocol for determination of conidial viability of the fungal entomopathogens Beauveria bassiana and Metarhizium anisopliae from commercial products. Journal of Microbiological Methods 119:44-52

Pasquetti M, Min ARM, Scacchetti S, Dogliero A \& Peano A. 2017. Infection by Microsporum canis in paediatric patients: a veterinary perspective. Veterinary Sciences 4(3):46

Rebey IB, Bourgou S, Debez IBS, Karoui IJ, Sellami IH, Msaada K, Limam F \& Marzouk B. 2012. Effects of extraction solvents and provenances on phenolic contents 
and antioxidant activities of cumin (Cuminum cyminum L.) seeds. Food and Bioprocess Technology 5(7):2827-2836

Rex JH, Pfaller MA, Galgiani JN, Bartlett MS, Espinel-Ingroff A, Ghannoum MA, Lancaster M, Odds FC, Rinaldi MG, Walsh TJ \& Barry AL. 1997. Development of interpretive breakpoints for antifungal susceptibility testing: conceptual framework and analysis of in vitro-in vivo correlation data for fluconazole, itraconazole, and candida infections. Subcommittee on Antifungal Susceptibility Testing of the National Committee for Clinical Laboratory Standards. Clinical Infectious Diseases 24(2):235-247

Roemer T and Krysan DJ. 2014. Antifungal drug development: challenges, unmet clinical needs, and new approaches. Cold Spring Harbor Perspectives in Medicine 4(5):a019703

Rubini B, Shanthi G, Soundhari C \& Rajarajan S. 2013. Antifungal activity of Terminalia chebula and Terminalia catappa on two dermatophytes. Open Access Journal of Medicinal and Aromatic Plants 4(2):15-19

Seyedmousavi S, Guillot J, Arne P, de Hoog GS, Mouton JW, Melchers WJ \& Verweij PE. 2015. Aspergillus and aspergilloses in wild and domestic animals: a global health concern with parallels to human disease. Medical Mycology 53(8):765797

Stein AC, Sortino M, Avancini C, Zacchino S \& von Poser G. 2005. Ethnoveterinary medicine in the search for antimicrobial agents: antifungal activity of some species of Pterocaulon (Asteraceae). Journal of Ethnopharmacology 99(2):211214

Terças AG, de Sousa Monteiro A, Moffa EB, dos Santos JRA, de Sousa EM, Pinto ARB, da Silva Costa PC, Borges ACR, Torres LMB, Barros Filho AKD, Fernandes ES \& de Anrade Monteiro C. 2017. Phytochemical characterization of Terminalia catappa Linn. extracts and their antifungal activities against Candida spp. Frontiers in Microbiology 8:595

Turkmen N, Sari F \& Velioglu YS. 2006. Effects of extraction solvents on concentration and antioxidant activity of black and black mate tea polyphenols determined by ferrous tartrate and Folin-Ciocalteu methods. Food Chemistry 99(4):835-841

Verma J. 2012. Data analysis in management with SPSS software. Springer Science and Business Media

Wang J, Wang W, Xiong H, Song D \& Cao X. 2020. Natural phenolic derivatives based on piperine scaffold as potential antifungal agents. BMC Chemistry 14(1):1-12

Zhang J-D, Xu Z, Cao Y-B, Chen H-S, Yan L, An M-M, Gao P-H, Wang Y, Jia X-M \& Jiang Y-Y. 2006. Antifungal activities and action mechanisms of compounds from Tribulus terrestris L. Journal of Ethnopharmacology 103(1):76-84 